\title{
Daily Surface Wind Fields Produced by Merged Satellite Data
}

\author{
Abderrahim Bentamy ${ }^{1}$, Kristina B. Katsaros ${ }^{2}$, William M. Drennan ${ }^{3}$, and Evan B. Forde ${ }^{2}$ \\ Scatterometers and radiometers on several polar-orbiting satellites routinely \\ produce oceanic surface wind field data. For this study, we merged the NASA \\ scatterometer (NSCAT) data with scatterometer data from the European Remote \\ Sensing (ERS) satellite 2, and the wind speeds from two of the Special Sensor \\ Microwave/Imagers (SSM/I) and produced daily $1^{\circ}$ latitude by $1^{\circ}$ longitude \\ gridded wind fields over the global ocean for September 1996 through June \\ 1997. This time period coincides with the lifetime of the NSCAT aboard \\ ADEOS-1. We created these wind fields by utilizing the Kriging technique with \\ its associated variograms, which consider both space and time wind vector \\ structures. The resulting daily wind fields, when compared with moored-buoy \\ wind speed and direction measurements, resulted in a root-mean-square (rms) \\ difference of less than $1.5 \mathrm{~m} / \mathrm{s}$. No significant difference was found between \\ statistical parameters estimated over the equatorial zone and middle latitudes. To \\ investigate the global patterns of these new satellite wind fields, comparisons \\ with the National Environmental Prediction Center's (NCEP) re-analysis pro- \\ ducts have been carried out. The satellite data and the NCEP products have a \\ similar statistical error structure, but the merged wind fields provide complete \\ coverage at much higher spatial resolution. Accurate surface wind speed \\ estimates are an important factor in determining the velocity and magnitude of \\ air-sea gas exchange.
}

\section{INTRODUCTION}

This paper studies and analyzes the global gridded wind field calculations derived from satellite wind observations. Three instruments that provide estimates of surface winds

\footnotetext{
'Institut Français de Recherche Pour l'Exploitation de la Mer, Plouzané, France

${ }^{2}$ NOAA/Atlantic Oceanographic and Meteorological Laboratory, Miami, Florida

${ }^{3}$ University of Miami/Rosenstiel School of Marine and Atmospheric Science, Miami, Florida
}

Gas Transfer at Water Surfaces

Geophysical Monograph 127

Copyright 2002 by the American Geophysical Union over the global oceans at different scales are used: the scatterometer mounted on the European Remote Sensing (ERS) satellite; the NASA scatterometer (NSCAT) on board the Advanced Earth Observing Satellite (ADEOS-1); and the Special Sensor Microwave/Imager (SSM/I) deployed on board the Defense Meteorological Satellite Program (DMSP) satellites F10, F11, F13, and F14. These satellites are in sun-synchronous orbits at about $800 \mathrm{~km}$ height with $98^{\circ}$ inclination.

Gridded surface wind parameter estimates, including wind vectors, stresses, curl, and divergence, have been made available since August 1991 from ERS- 1 and ERS-2 scatterometers, and between September 1996 and June 1997 from NSCAT. These gridded wind fields have been used extensively in global wind studies [Bentamy et al., 1998] and in ocean model forcing [Grima et al., 1999]. Such studies, performed for the tropical Pacific area, indicate that the scatterometer gridded wind fields compare 


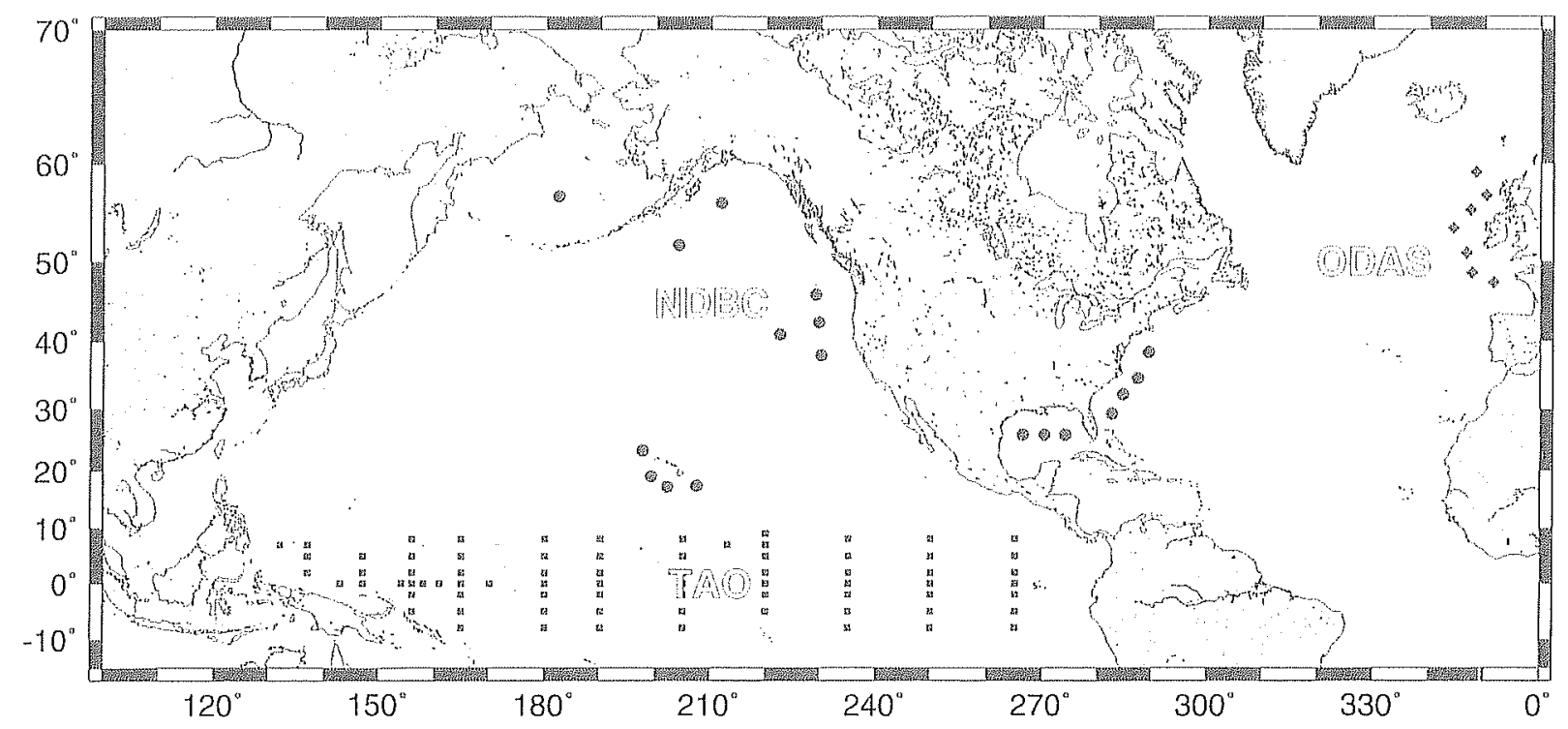

Figure 1. Locations of NDBC (circle), TAO (square), and ODAS (diamond) buoys.

quite well with averaged wind speed and direction estimated from buoy measurements. For instance, the rootmean-square (rms) errors of wind parameters indicate that the statistical differences between weekly buoy and ERS-1 scatterometer wind estimates are about $0.90 \mathrm{~m} / \mathrm{s}$ for wind speed, $1.50 \mathrm{~m} / \mathrm{s}$ for the zonal wind component, and $1.60 \mathrm{~m} / \mathrm{s}$ for the meridional component. Furthermore, the results obtained from experiments forcing an ocean model with gridded scatterometer wind fields show that the correlations estimated from the thermocline ERS-1 simulation and from buoy measurements are statistically significant, and their mean value is greater than 0.70 . Boutin et al. [1999] verify that satellite derived wind observations can provide quality estimates of the global ocean wind fields, especially as they relate to air-sea gas exchange studies.

This research investigates the improvement of the temporal resolution and the accuracy of gridded wind fields calculated by merging ERS-2, NSCAT, and SSM/I wind observations. Since it is well known that surface wind speed is an important variable for estimating gas transfer velocity [Wanninkhof, 1992], this work may also help improve regional and global estimates of air-sea gas fluxes.

This paper is organized into two parts. Section 2 deals with data used in this study and briefly describes the objective method used for global wind analysis. The effects of sampling errors due to the polar satellite-sampling scheme is investigated and results are provided. Some examples of resultant wind fields are shown. Section 3 deals with the estimation of the accuracy of scatterometer wind fields. An objective evaluation of the study's success will be a com- parison of our satellite estimates to surface winds derived from moored buoy measurements.

\section{DATA AND METHODS}

\subsection{Satellite Wind Observations}

The daily wind fields are calculated from ERS-2 and NSCAT scatterometers and SSM/I wind observations. The calculation is performed during the NSCAT period September 16, 1996 to June 29, 1997. The scatterometers provide near-surface wind vectors (wind speed and direction at $10-m$ height) over the global oceans with a spatial resolution of $50 \times 50$ and $25 \times 25 \mathrm{~km}^{2}$, respectively, over a swath of $500-\mathrm{km}$ width for ERS-2, and two swaths of $600 \mathrm{~km}$ each for NSCAT. SSM/I allows the estimation of surface wind speed with a spatial resolution of $25 \mathrm{~km}$ over a swath of $1400-\mathrm{km}$ width. The number of ERS-2, NSCAT, and SSM/I orbits are about 14.3 per day each. They cover the global oceans within two to three days. Furthermore, the ERS scatterometer makes about 79,500 wind observations per day, NSCAT makes 190,000, while the SSM/I makes about 420,000.

The accuracy of ERS and NSCAT retrieval wind speeds and direction and SSM/I wind speeds were determined through a comparison with buoy wind measurements [Quilfen et al., 1994; Graber et al., 1996; Graber et al., 1997; Bentamy et al., 1999]. Three buoy networks were used to estimate the quality of the retrieved scatterometer wind vectors (Figure 1): the National Data Buoy Center (NDBC) buoys off the U.S. Atlantic, Pacific, and Gulf 

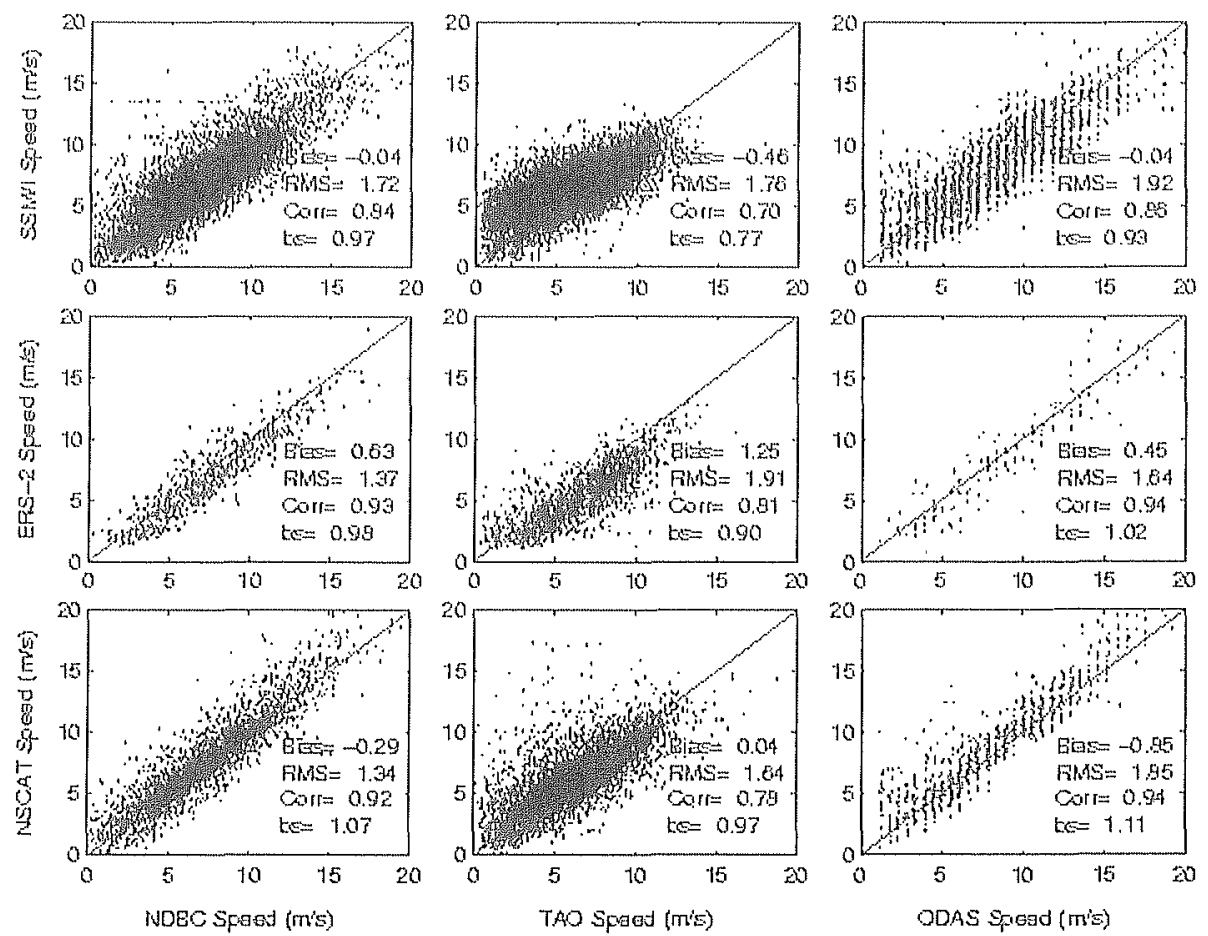

Figure 2. Scatterplots of collocated wind speeds derived from buoy measurements (NDBC, TAO, and ODAS) and from scatterometer observations (SSM/I, ERS-2, and NSCAT).

coasts maintained by the National Oceanic and Atmospheric Administration (NOAA); the Tropical Atmosphere Ocean (TAO) buoys located in the tropical Pacific Ocean and maintained by NOAA's Pacific Marine Environmental Laboratory (PMEL); and the European buoys off European coasts called ODAS and maintained by the United Kingdom's Meteorological Office (UKMet) and MeteoFrance. The calculation of buoy wind speed at $10-\mathrm{m}$ height in neutral conditions is performed using the Liu-KatsarosBusinger (LKB) model [Liu et al., 1979]. For the three networks, only hourly buoy wind speed and direction estimates are used in the scatterometer/buoy wind comparisons.

The results obtained by Graber et al. [1996] indicated that the ERS-1 scatterometer wind speeds are biased low compared to buoy winds. The bias values derived from ERS-1/NDBC and from ERS-1/TAO comparisons are $0.30 \mathrm{~m} / \mathrm{s}$ and $1 \mathrm{~m} / \mathrm{s}$, respectively. The corresponding $\mathrm{rms}$ values are $1.13 \mathrm{~m} / \mathrm{s}$ and $1.38 \mathrm{~m} / \mathrm{s}$. The comparisons between wind direction retrieved from the ERS-1 scatterometer and measured by buoys provided an rms error of $24^{\circ}$ for both buoy networks. Using similar collocation procedures, Graber et al. [1997] showed that the difference between NDBC and NSCAT wind speeds has mean and rms values of $0.14 \mathrm{~m} / \mathrm{s}$ and $1.22 \mathrm{~m} / \mathrm{s}$, respectively. For the NSCAT wind direction, the rms error is about $24^{\circ}$. The results inferred from NSCAT/TAO comparisons [Caruso et al., 1999] indicated that for wind speed the bias is very low, and the rms difference is about $1.55 \mathrm{~m} / \mathrm{s}$, while for wind direction, the rms difference is about $20^{\circ}$. The results obtained from the ERS-2 scatterometer/buoy comparisons are quite similar to those obtained for ERS-1, except that the overall bias of ERS-2 scatterometer wind speed is higher [Quilfen et al., 1999]. The accuracy of SSM/I wind estimates is tested by comparing with NDBC [Goodberlet et al., 1989] and TAO [Halpern, 1993; Bentamy et al., 1999] buoy wind measurements. The results indicate that for most wind ranges, the bias between SSM/I and buoy wind speed is low, but it is high for low wind speed $(<3 \mathrm{~m} / \mathrm{s})$. The standard deviation of the difference is $<2 \mathrm{~m} / \mathrm{s}$.

Figure 2 shows scatter plots of a comparison of SSM/I, ERS-2, and NSCAT wind speeds with buoy winds at $10 \mathrm{~m}$ for NDBC, TAO, and ODAS buoys. Most of the statistical parameters provided within each figure are quite similar to those obtained from previous studies cited above. However, the bias on ERS-2 and SSM/I wind speeds are significant and require correction. To enhance the statistical significance of the retrieved ERS-1/2 scatterometer wind speeds, a collocated data set between ERS-1/2 and NDBC buoy measurements was generated. All valid ERS-1/2 scatterometer measurements obtained within 1 hour and $50 \mathrm{~km}$ 
from buoy measurements during the period March 1992November 1998 were used to derive a new version of the ERS C-band model [Bentamy et al., 1994], which minimizes the bias seen in Figure 2. The latter is used to retrieve ERS-1/2 scatterometer wind speed observations from measured backscatter coefficients. For SSM/I, the method developed by Bentamy et al. [1999] is used to improve SSM/I wind speed estimates with respect to buoy comparisons. Hence, the ERS-2, NSCAT, and SSM/I merged gridded wind fields are calculated from the ERS-2 and SSM/I corrected wind speeds. SSM/I wind speed $\left(U_{s . s m i}\right)$ is calculated over each SSM/I cell $(25 \mathrm{~km})$ using the following formula:

$$
U_{s s m i}=f\left(T_{B}\right)+f(W V)
$$

where $T_{B}$ and $W V$ indicate brightness temperature and water vapor content, respectively. The global analysis of wind direction is performed from the standard ERS-2 and NSCAT wind directions.

\subsection{Objective Method}

The details of the gridded wind field calculations from remotely-sensed wind observations are provided by Bentamy et al. [1996, 1999]. Briefly, the radar and radiometer wind observations are objectively analyzed using a method based on the Kriging approach [Wackernagel, 1995]. At each grid point of $1^{\circ} \times 1^{\circ}$ in longitude and latitude, the estimation of the daily wind vector is obtained consistently by interpolation of wind speeds, zonal components, and meridional components. For each variable, the method determines an estimator at each grid point, $X_{0}$, using $n$ observations at point $X_{i}$ :

$$
\hat{U}=\sum_{i=1}^{N} \lambda_{i} V\left(X_{i}\right), \quad \sum_{i=1}^{N} \lambda_{i}=1
$$

where $\hat{U}$ stands for wind speed, zonal component, or the meridional component estimator; $V\left(X_{i}\right)$ are the scatterometer observations at $X_{i}$, and $X_{i}$ represents spatial and temporal coordinates. The weights $\lambda_{i}$ are determined as the minimum of the linear system named Kriging:

$$
\begin{aligned}
& -\sum_{\substack{i=1 \\
i=1}}^{n} \lambda_{i} \Gamma(i, j)+\Gamma(j, 0)-\tau_{1}-\tau_{2} S(j)+\lambda_{j} \sigma 2=0 \\
& \sum_{\substack{i=1 \\
i=1}}^{n} \lambda_{i}=1 \quad j=1, n \\
& \sum_{\substack{n=1 \\
i=1}}^{n} \lambda_{i} S(i)=S(0)
\end{aligned}
$$

where $\Gamma$ is the structure function providing the spatial and temporal behavior of the variable to be estimated. The estimation of $\Gamma$ is obtained from the ERS- 1 scatterometer wind speed, zonal component, and meridional component observations. The variable $S(i)$ represents a regionalized variable and is considered as deterministic. Its values are inferred from SSM/I corrected wind speed estimates. Over an ocean basin, scatterometer and SSM/I winds are assumed to be related by: $E(U(i))=a_{0}+b_{0} S(i) . U$ is the scatterometer wind variable, $E\left(\right.$ ) indicates the first moment, and $a_{0}$ and $b_{0}$ are constant. Furthermore, the Kriging method provides an expression for variance error, named the Kriging error.

In practice, the calculation of merged satellite gridded wind fields using the Kriging method is based on the following items:

(1) The remotely sensed wind products, including backscatter measurements, brightness temperatures, and retrieved wind vectors, extracted from the Centre ERS d'Archivage et de Traitment (CERSAT)/WiNd Field (WNF) database. Only validated data, according to standard quality controls, are used.

(2) At each ERS-1/2 scatterometer cell $(50 \mathrm{~km})$, a new wind speed is estimated from the three backscatter coefficients using the new C-band model function. In this study, the wind direction selected by the operational algorithm (WNF or NSCAT) is chosen. However, for low wind conditions, a comparison between each scatterometer wind direction solution and European Centre for Medium Range Weather Forecasts (ECMWF) wind direction, interpolated in space and time on the scatterometer cell, is performed. The closest scatterometer wind direction from ECMWF is selected. The zonal and meridional wind components are estimated from scatterometer wind speed and direction.

(3) At each SSM/I cell, 10-m surface wind speed is estimated in the absence of rain, using equation (1).

(4) The world oceans are divided into boxes with constant grid spacing in latitude and longitude. In this study, the spatial resolution is $1^{\circ} \times 1^{\circ}$ in latitude and longitude. All available scatterometer wind observations at nearly the same time (less than 1 hour) are averaged arithmetically in each box. Similar averaging computation is done for SSM/I winds.

(5) At each grid point, the determination of a neighborhood containing the scatterometer data used to estimate wind vectors (wind speed, zonal, and meridional components) is performed. It is quite a sensitive step. Indeed, due to the highly irregular spatial and temporal arrangement and the density of the scatterometer wind observations, the determination of a local neighborhood is not straightforward. The neighborhood is determined as successive circles centered on the grid point. The radius of these circles correspond to the variogram parameters. The maximum number of observations in a grid point neighborhood 
Table 1. Comparison of averaged daily wind speed and direction estimated from NDBC, TAO, and ODAS buoy measurements and from SSM/I, ERS-2, and NSCAT wind observations.

\begin{tabular}{|c|c|c|c|c|c|c|c|c|c|}
\hline \multirow[b]{2}{*}{ Data Sel } & \multirow[b]{2}{*}{$\begin{array}{c}\text { Buoy Wind Speed } \\
\text { Range }(\mathrm{m} / \mathrm{s})\end{array}$} & \multirow[b]{2}{*}{ Length } & \multicolumn{5}{|c|}{ Wind Speed } & \multicolumn{2}{|c|}{ Wind Direction } \\
\hline & & & $\begin{array}{l}\text { Bias } \\
(\mathrm{m} / \mathrm{s})\end{array}$ & $\begin{array}{l}\mathrm{Rms} \\
(\mathrm{m} / \mathrm{s})\end{array}$ & $\begin{array}{l}\text { Correlation } \\
\text { Cocfficient }\end{array}$ & Slope & Intercept & $\begin{array}{l}\text { Bias } \\
\text { (deg) }\end{array}$ & $\begin{array}{c}\text { Std } \\
\text { (deg) }\end{array}$ \\
\hline NDBC/Satellite & $0-24$ & 3932 & -0.15 & 1.79 & 0.90 & 0.96 & 0.4 .1 & 5 & 25 \\
\hline TAO/Satellitc & $0-20$ & 13427 & 0.04 & 1.61 & 0.88 & 0.81 & 1.40 & 3 & 23 \\
\hline ODAS/Satellite & $0-24$ & 870 & -0.89 & 2.56 & 0.82 & 0.90 & 1.71 & 2 & 30 \\
\hline
\end{tabular}

is 1200 . This data set is then sorted by time, and for each hour the closest scatterometer observations from the grid point are used for wind vector estimation.

\section{SATELLITE/BUOY AVERAGED WIND COMPARISONS}

For each day (September 16, 1996-June 29, 1997), mean values of buoy wind speed and zonal and meridional components are computed arithmetically. Daily means are computed for all NSCAT periods for which at least 12 hour buoy measurements are collected. For each averaging period, the closest scatterometer grid point $\left(1^{\circ} \times 1^{\circ}\right)$ to each buoy location is selected. Therefore, a collocated data set between scatterometer-gridded wind fields (averaging objective method) and buoy-averaged winds are performed for NDBC, TAO, and ODAS buoy networks. Results are then compared using standard statistics.

Table 1 provides the main statistical parameters characterizing wind speed and direction comparisons. The wind speed correlation coefficients range from 0.82 to 0.90 and indicate a good consistency between satellite and buoyaveraged winds. The rms values of the differences of buoysatellite wind speeds do not exceed $1.80 \mathrm{~m} / \mathrm{s}$ over NDBC and TAO networks. Results derived from ODAS/satellite comparisons show a higher bias and rms values of $0.89 \mathrm{~m} / \mathrm{s}$ and $2.56 \mathrm{~m} / \mathrm{s}$, respectively. The latter are mainly due to very few comparison data points, and to the high wind variability in the ODAS area (Figure 1). Furthermore, the statistics calculated by several meteorological centers (ECMWF, Commission on Marine Meteorology, UKMet) indicate that ODAS buoy wind speeds tend to be underestimated according to meteorological wind analysis (see ftp://ftp.shom.fr/meteo/qc-stats, site maintained by $\mathrm{P}$. Blouch).

In the NDBC area, buoy and merged satellite wind speeds agree quite closely (slope of 0.96 , with intercept 0.41 ) after the linear regression fit. Comparisons between buoy and satellite winds in the tropical Pacific Ocean give a regression line slope of about 0.80 , suggesting an overestimation of low wind speed and underestimation of high wind speed by the merged satellite wind fields compared to TAO winds. The scatterometer wind fields are consistently high compared to the ODAS weekly-averaged wind speeds. Inspection of the calculation of the statistical parameters based on the buoy wind speed ranges (not shown) indicates that their values are increased by some outlier points at low and high wind speeds.

For wind direction, no systematic bias is found, and the overall bias and standard deviation about the mean angular difference are less than $5^{\circ}$ and $30^{\circ}$, respectively. These results are consistent with the calibration/validation of the scatterometers against buoy [Graber et al., 1996, 1997; Caruso et al., 1999]. For instance, in the tropical Pacific area where the wind direction is quite steady, the standard deviation calculated for buoy wind speeds higher than $5 \mathrm{~m} / \mathrm{s}$ does not exceed $17^{\circ}$.

The agreement between scatterometer and buoy-averaged wind fields was investigated through time series comparisons with the NDBC, TAO, and ODAS buoy arrays. Figure 3 shows examples of daily averaged time series of wind speed at five buoy locations, representing various latitudes, in the NDBC array. The comparisons indicate that the matchups are strongly correlated, and their geographical features compare well. For instance, the correlation coefficient is greater than 0.80 at all locations. The lowest correlation values, varying between 0.80 and 0.89 , are found in the TAO array. At TAO locations $95^{\circ} \mathrm{W}$ 0 and $95^{\circ} \mathrm{W}-2^{\circ} \mathrm{N}$, the difference between buoy and scatterometer wind speeds is consistent, and the bias reaches $1 \mathrm{~m} / \mathrm{s}$. Several error sources can explain the discrepancies between scatterometer and TAO winds. For instance, since the scatterometer measures winds relative to the moving ocean surface, if the current is in the same direction as the wind, the scatterometer winds tend to be lower than buoy estimates of surface wind, relative to the solid earth. In the ODAS array, scatterometer averaged wind speeds are consistently higher than buoy estimates. However, we notice that the bias between buoys and scatterometers tends to be large between October and December 1996. During this period, the correlation coefficient is only about 0.69 , which is $22 \%$ smaller than for the whole period. The comparisons between NDBC and scatterometer averaged wind speed time series does not exhibit any systematic bias. At some locations, such as $157.8^{\circ} \mathrm{W}-17.2^{\circ}$ (Figure $3 \mathrm{a}$ ) and $177.7^{\circ} \mathrm{W}-57^{\circ} \mathrm{N}$ ) (Figure 


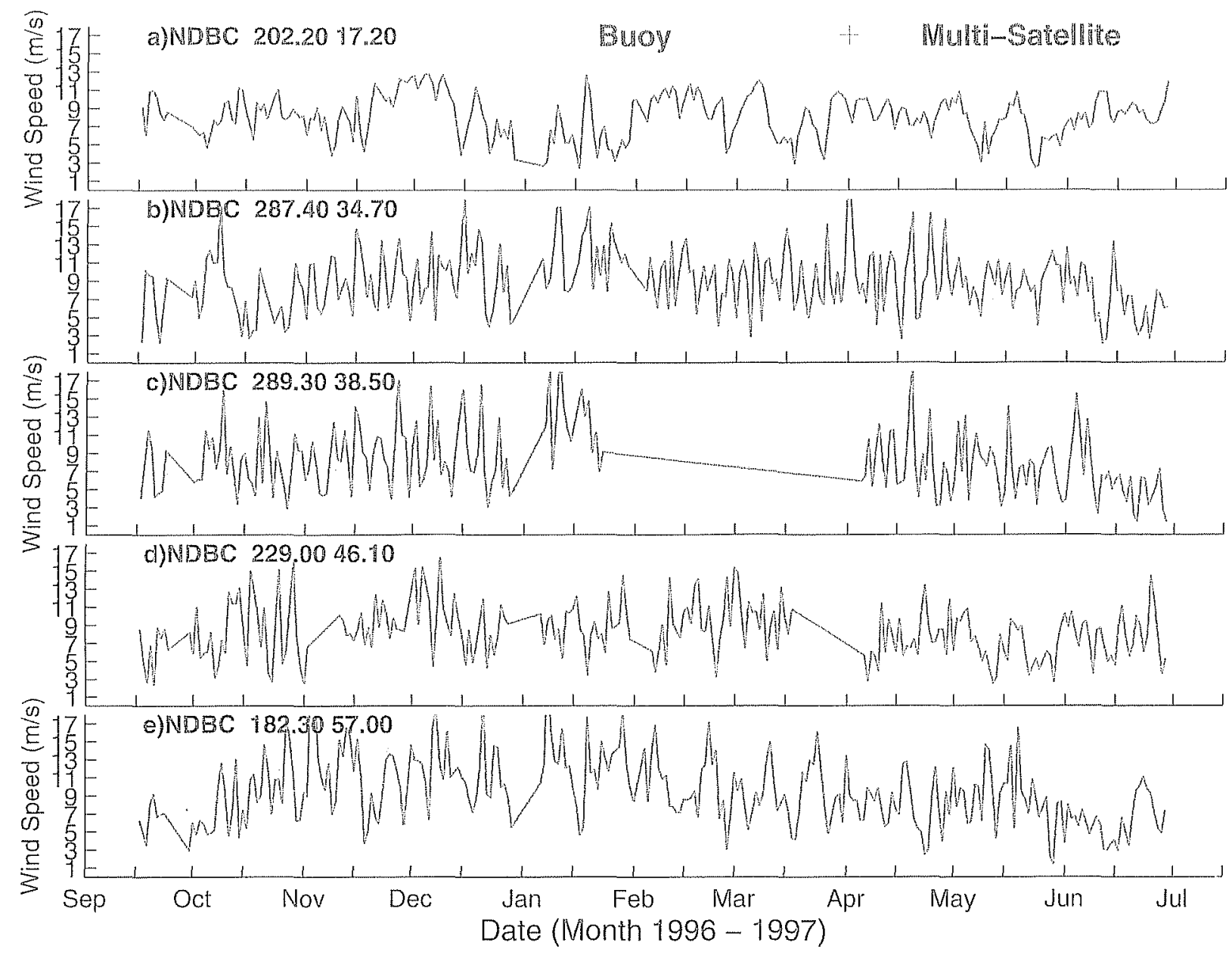

Figure 3. Time series of the daily averaged wind speed derived from merged satellite winds (red line) and from NDBC buoys (green line) at five NDBC locations.

3e), we found a seasonally-related data bias. The bias tends to be slightly positive in winter and negative in summer. This variation maly be related to the dependence of the wind speed residuals on buoy wind speed ranges.

A comparison of hourly winds from the merged satellite data with predictions from the NCEP re-analysis indicated good overall agreement. However, significant regional differences are apparent, particularly in the southern oceans (not shown).

\section{CONCLUSIONS}

By merging NSCAT data with scatterometer data from the ERS-2 satellite, and the wind speeds from two SSM/Is, we have produced daily $1^{\circ}$ latitude by $1^{\circ}$ longitude gridded wind fields over the global ocean for September 1996 through June 1997. The overall accuracy of the merged wind fields is excellent. Biases are $<0.7 \mathrm{~m} / \mathrm{s}$, rms and on the order of $2 \mathrm{~m} / \mathrm{s}$. When compared to moored buoy wind speed and direction measurements, our data have a rms difference of $<1.5 \mathrm{~m} / \mathrm{s}$. No significant difference was found between statistical parameters estimated over the equatorial zone and middle latitudes. Comparisons with NCEP's reanalysis products revealed that our merged satellite data and the NCEP products have similar statistical error structure, but the merged wind fields provide complete coverage at much higher spatial resolution. With the addition of QuikSCAT in 1999 and other satellites scheduled for launch soon, satellite derived global ocean wind fields will continue to be available to produce these types of daily wind field maps in the foreseeable future. Since accurate surface wind speed estimates are an important factor in determining the velocity and magnitude of air-sea gas exchange, our research may also help improve regional and global estimates of air-sea gas fluxes. 
Acknowledgments. The ERS-2 data were obtained from CERSAT, SSM/I data from Remote Sensing Systems, Inc, and NSCAT data from the Jet Propulsion Laboratory facility. The work was supported in part by NASA grant UPN261-75 to K.B. Katsaros.

\section{REFERENCES}

Bentamy, A., Y. Quilfen, P. Queffeulou, and A. Cavanie, Calibration of the ERS-I scatterometer C-band model, IFREMER Tech. Rep., DRO/OS-94-01, pp. 72, 1994.

Bentamy, A., Y. Quilfen, F. Gohin, N. Grima, M. Lenaour, and I. Servain, Deternination and validation of average wind lields from ERS-1 scatterometer measurements, Global Atmos. Ocean Syst., 4, 1-29, 1996.

Bentamy, A., N. Grima, and Y. Quilfen, Validation of the gridded weekly and monthly wind fields calculated from ERS-1 scatterometer wind observations, Global Atmos. Ocean Syst., 6 , 373-396, 1998

Bentamy, A., P. Queffeulou, Y. Quilfen, and K.B. Katsaros, Ocean surface wind fields estimated from satellite active and passive microwave instruments, IEEE Trans. Geos. Rem. Sens., 37 (5), 2469-2486, 1999.

Boutin, J., J. Etcheto, M. Rafizadeh, and D.C.E. Bakker, Comparison of NSCAT, ERS 2 active microwave instrument, Special Sensor Microwave Imager, and carbon interface ocean atmosphere buoy wind speed: Consequences for the air-sea $\mathrm{CO}_{2}$ exchange coefficient, J. Geophys. Res., 104, (C5), 11,375$11,392,1999$.

Caruso, M., S. Dickinson, K. Kelly, M. Spillane, L. Mangum, M. McPhaden, and L. Stratton, Evaluation of NSCAT scatterometer winds using equatorial Pacific buoy observations, Tech. Rep., Applied Physics Lab., Univ. of Washington, Seattle, WA, pp. 60,1999 .

Goodberlet, M.A., C.T. Swift, and J.C. Wilkerson, Remote sensing of ocean surface winds with the special sensor microwave/imager, J. Geophys. Res., 94, 14,547-14,555, 1989.

Graber, H.C., N. Ebuchi, and R. Vakkayil, Evaluation of ERS-1 scatterometer winds with wind and wave ocean buoy observa-
Lions, Tech. Rep., RSMAS 96-003, Div. of Applied Marine Physics, Univ, of Miani, FL, pp. 58, 1996.

Graber, H.C., A. Bentamy, and N. Ebuchi, Evaluation of NSCAT scatterometer winds with ocean buroy observations, Proc., NASA Scatterometer Science Simp., November 10-14. 1997. Maui, HI, pp. 106-107, 1997.

Grima, N., A. Bentany, K. Katsaros, Y. Quilfen, P. Delecluse, and C. Levy, Sensitivity of an oceanic general circulation model forced by satellite wind stress fields, J. Geophys. Res., 104 (C4), 7967-7989, 1999

Halpern, D., Validation of Special Sensor Microwave Imager monthly mean wind speeds from July 1987 to December 1989, IEEE Trans. Geos. Rem. Sens., 31 (3), 692-699, 1993.

Liu, W.T., K.B. Katsaros, and J.A. Businger, Bulk parameterization of air-sea exchanges of heat and water vapor including the molecular constraints at the interface, J. Atmos. Sci., 36, 17221735, 1979

Quilfen, Y., and A. Bentamy, Calbration/validation of ERS-1 scatterometer precision products, Proc., Internat. Geosci. and Remote Sens. Symp. (IGARSS'94), Pasedana, CA, August 8-12, 1994, pp. 945-947, 1994

Quilfen, Y., A. Bentamy, K.B. Katsaros, and G. Lorand, Estimation of ocean-atmosphere furbulent fluxes from satellite measurements, Proc, Internat. Conf. on the Ocean Observing System for Climate (OCEANOBS99), St. Raphael, France, October 18-22, 1999, Centre National d'Etudes Spatiales, 2000.

Wackernagel, H., Multivariate Geostatistics, Springer-Verlag p. 256, 1995 .

Wanninkhof, R., Relationship between gas exchange and wind speed over the ocean, J. Geophys. Res., 97, 7373-7381, 1992.

A. Bentamy, Institut Français de Recherche Pour l'Exploitation de la Mer, B.P. 70, 29280 Plouzané, France.

W.M. Drennan, University of Miami, Rosenstiel School of Marine and Atmospheric Science, 4600 Rickenbacker Causeway, Miami, FL 33149

E.B. Forde and K.B. Katsaros, NOAA/Atlantic Oceanographic and Meteorological Laboratory, 4301 Rickenbacker Causeway, Miami, FL 33149. 